\title{
A Review on the Effect of Using Dictogloss Tasks and Fake Scoring on Children's Dictation Ability
}

\author{
Batool Faghani ${ }^{1}$, Ali Derakhshan ${ }^{2} \&$ Ali Zangoei $^{3}$ \\ ${ }^{1}$ Department of English Language Teaching, Gorgan Branch, Islamic Azad University, Gorgan, Iran \& Department \\ of English Language Teaching, Golestan Science and Research Branch, Islamic Azad University, Gorgan, Iran \\ ${ }^{2}$ Assistant Professor in Applied Linguistics, Department of English Language and Literature, Golestan University, \\ Iran \\ ${ }^{3}$ University of Gonabad, Department of English Language and Literature, Iran \\ Correspondence: Ali Derakhshan, Assistant Professor in Applied Linguistics, Department of English Language and \\ Literature, Golestan University, Iran. E-mail: a.derakhshan@gu.ac.ir
}

Received: July 29, 2015

doi:10.5430/elr.v4n3p58
Accepted: August 19, 2015

Online Published: September 4, 2015

URL: http://dx.doi.org/10.5430/elr.v4n3p58

\begin{abstract}
Writing is one of the important language skills that should be mastered by the foreign language learners to convey their concepts in written form, so teachers should contemplate on different applicable techniques to promote this skill. One of these techniques is dictogloss task. Dictogloss task is a technique of dictation method that can be used for teaching writing cooperatively. It has four steps which are preparation, dictation, reconstruction, and analysis and correction. Dictogloss procedure is practical and flexible enough to account for the needs, interests, and learning preferences of learners. Kids and even adults need reassurance and flexibility from their teachers while learning. They need not to be interrupted while producing, and sometimes their mistakes are better not to be announced and corrected at the time. A motivational strategy to reach that goal was to ignore their writing mistakes in scoring by simply and slightly showing them that the mistaken part could have been written in the correct form. Given the background of unsatisfactory number of studies on improving children language learning performance, especially, their writing in pre-school age, this review study is aimed to highlight a useful technique in the language teaching activities, not just English. It has an endeavor to find the influence of giving fake high scores in a dictogloss task on kids' dictation ability. It is recommended that teachers should be encouraged to voice their viewpoints and be capable of any required changes regarding their class situation and be able to rely on themselves rather than books. In spite of being fair, it is sometimes needed to lessen the strictness towards some students. It is concluded that fake high scoring on a permanent dictogloss task is a suitable, applicable, and appropriate device for EFL teachers and learners to achieve their educational aims.
\end{abstract}

Keywords: Dictation, Dictogloss, Writing Ability

\section{Introduction}

As old as the existence age of the classrooms, there have been teachers who committed to encouragement and promotion of classroom populations. Traditional English teach-ing methods, often include translating structures from the target language to the mother tongue that has no attention to the situation of language teaching and learning (Bollin, 2003; Faghani, 2015). Many Eng $\neg$ lish teachers around the world may still prefer direct instruction even though they are often free to select from a vari $\urcorner$ ety of methods or strategies (Bollin, 2003). Undoubtedly, the fact is that, teachers who were taught by traditional methods tend to contin $\neg$ ue teaching with the same methods they had been taught; teachers typically have a tendency to teach the way they were taught (Anderson, Standerford \& Imdieke, 2010; Britzman, 1991; Faghani \& Derakhshan, in press; Goodlad, 1984; Hansen, 1995; Kumaravadivelu, 2003; Prabhu, 1987; Stewart, Silva, \& González, 2014; Walia, 2012).

Moreover, relying on the results of a study by Herbert (2010) shows that even if the best studying situations are prepared for the students in a most comfortable classrooms, they will not be successful if they believe that they cannot learn, or if they identify themselves as bumbling learners. This will be the case in spite of attempts by the teacher to teach them efficient behavioral routines and learning strategies. As Nevola (2002) states, we must also stop blaming the children for having learning difficulties. Self-esteem, which shows the extent to which the 
individual believes in himself based on the Coopersmith's (1967) definition, is a personal judgment of value and praise which is expressed in attitudes that an individual holds towards himself. It is believed that learners' self-esteem would be increased by giving them fake higher scores; similarly, de Andres reports a research on the value of self-esteem in language learning (de Andres as cited in Tomlinson, 2010, p. 90). Furthermore, Kaga (1991) and Savignon (1982) suggested dictation as a relatively simple, reliable and valid indirect measure of functional language skills, and it is gaining popularity as a test of placement and proficiency in L2 programs of all kinds. Teachers must be ready to accept the new methodologies and teaching tools that are available to them, and to the learners they teach. Teachers got their name because they want to teach. They are not teachers if they accept the learners' failure as an indispensable rule. If a teaching tool does not work as well, then it must be stopped using. (Nevola, 2002). The problem is not with the learners, indeed, it is with the teaching methods.

One of the teaching and testing spotlights that can be zoomed on is dictation which is an effective means of helping teachers and learners during language teaching/learning processes to promote learning and also testing language proficiency if it is utilized in a proper procedure while considering all four skills in learning a foreign/second language (Ghaffarzade, 2013; Brodkey, 1972). Similarly, Rahimi (2008) points out that dictation, though widely known as a testing device, can be considered as a good learning technique to improve learners' proficiency. It is believed by the researchers that the time of passive technician teachers, those who just follow the teaching instruction in a program that concentrates more on the education part than on the teacher part (Kumaravadivelu, 2003), is over. Teachers should contemplate upon new methods of teaching or new tasks to involve more in the learning process. Dictogloss is one of these techniques which is a relatively recent procedure in language teaching, and in fact it differs from dictation in both procedure and objectives (Wajnryb, 1990). According to Mehdiabadi and Arabmofrad (2014), among a variety of several tasks that may affect learners' behaviors such as motivation, anxiety and sense of responsibility, dictogloss is known as one of the well-known output oriented activities and a type of focus-on-form task. The dictogloss procedures demonstrate a learning approach where students have chances and opportunities to integrate reading, writing, listening, and speaking skills through social interaction (Stewart et al., 2014). Therefore, the purpose of the present review study is to see the effects of fake high scores to learners' dictations, and hence, their hypothesized increased proficiency level of kids. For all practical purposes, the researchers were interested to find any effect or relationship between ignoring weak learners written mistakes and making them motivated to be more active in performing well in their dictation.

\section{Defining Dictation}

Dictation is the activity of writing down what is orally said or read. Dictation has been proposed as a relatively simple yet reliable and valid indirect measure of functional language skills and is gaining in popularity as a test of placement and proficiency in L2 programs of all kinds (Savignon, 1982).

There have been, to the best of our knowledge, almost no attempts to find valid ways to improve dictation. Since the input (aural), the output (written), and the process in both dictation and transcribing are almost the same, transcribing seems to be a valid way to practice and improve. (Afsharrad \& Sadeghi Benis, 2014, p. 2203)

Davis and Rinvolucri (2002) have also defined dictation as decoding sounds in aural input and then recoding them in writing. Afsharrad and Sadeghi Benis (2014) have recommended dictational transcribing exercise as one of the techniques to help elementary learners improve their language proficiency. Richards and Schmidt (2002) have demarcated dictation as a technique used in both language teaching and language testing in which a passage is read aloud to students or test takers, with pauses during which they must try to write down what they have heard as accurately as possible.

Dictation was firstly associated with the Grammar Translation Method and was neglected with the dominance of Audio Lingual Method in the 1960s. However, it regained popularity later because a) it highly correlates with tests of overall language proficiency and b) it tests language as a whole as opposed to testing language components in isolation. (Afsharrad \& Sadeghi Benis, 2014, p. 2204)

Being influenced by changing attitudes in the language teaching area, dictation has grown and faded in popularity throughout the history of language teaching. It is closely accompanied with Grammar Translation Method. By the emergence of Natural Method using dictation declined since this method gives more weight to oral skills of listening and speaking while teaching reading and writing is discouraged. Dictation regained legitimacy in 1970 when search for integrative measures of language proficiency initiated. Different varieties of dictation have sustained to be used as a valid device in teaching and testing since then (Afsharrad \& Sadeghi Benis, 2014). 
In standard dictation the text is usually played for three times. In the first and third times, the text is read at normal speech rate without any silences. The second time, includes pauses in order to allow time for the test-takers to write what they hear (Jafarpur \& Yamini, 1993).

\subsection{Dictation as a Testing Device}

Dictation as a device in both testing and teaching has been controversial in the area of SLA (Afsharrad \& Sadeghi Benis, 2014).

Using dictation as an instrument to measure general language proficiency has been popular for centuries (Farhady \& Malekpour, 1997). Oller (1972), have even claimed that dictation is more reliable and more valid than any other types of traditional methods of testing language proficiency.

Farhady and Malekpour (1997) state that dictation is a valid measure of language proficiency because it enjoys in certain characteristics far beyond mere spelling. First, dictation is believed to be a demanding test in which multiple linguistic components as well as language skills are measured instantaneously. Second, it activates the learners' internalized expectancy grammar and yields considerable information concerning one's overall language proficiency. Third, it meets the criteria of pragmatic tests provided that the materials are selected from natural context with appropriate length to tap the learners' short-term memory.

Oller and Perkins (as cited in Farhady \& Malekpour, 1997, p. 204) maintain that dictation task requires the processing of temporally constrained sequences of material in language processing tasks. Oller and Perkins (as cited in Farhady \& Malekpour, 1997, p. 204) claim that the task of dividing up the parts of speech and writing down what is heard needs figuring out the meaning of the material, i.e., relating linguistic context to the extra-linguistic context. Fourth, it reasonably mirrors what people do when they use language for communicative purposes authentically. This characteristic leads dictation to be a test of communicative performance (Canale \& Swain, as cited in Farhady \& Malekpour, 1997, p. 204). And fifth, dictation is used these days for several purposes including determining the students' ability to understand the language of instruction, placing foreign students in suitable study courses, and measuring the comprehension level of students regarding the discourse of a special subject matter. That is why dictation shows a significant harmony with other kinds of traditional tests (Farhady \& Malekpour, 1997).

From a testing point of view, dictation is generally known as a measure of overall language proficiency. But, it has met a lot of conflicts. Lado (1961), for instance, believes that dictation is not a good device to measure any aspect of language because almost everything is dictated to testees.

Dictation was also considered as a complicated technique which was of little use in authentic activity (Bennett, 1968). Kaga (1991) and Faghani (2015) contends that dictation is a reasonably valid and reliable measure of language proficiency in Japanese and English and suggested that dictation would be an effective measure of language proficiency even if a target language has a very close relationship between its pronunciations.

Rivers (1968) believed dictation as a teaching device but not as a testing device. Oller (1979) has considered dictation as a type of integrative test, which requires a learner to use several language skills at the same time. "There are many researchers who work on dictation as a useful tool in learning/teaching a language", Oller (1979) believed. Harris $(1969$, p. 5) considered dictation as an "uneconomical" and "imprecise" testing device. Believing that it tended to test many interconnected elements at the same time. This disapproval of dictation may have been the result of inadequacies of the psychological and linguistic theories which were used as the basis of language teaching methods in the 1950s and 1960s. Based on structural linguistics, language is broken down to its component parts and each part is taught and tested in isolation. According to behaviorisms, learning involves habitual development which is achieved in language learning through verbal practice. Accordingly, dictation which integrated different skills especially listening and writing with less emphasis on speaking was rejected (Jafarpur \& Yamini, 1993).

\section{Defining Dictogloss}

A dictogloss is a relatively recent procedure in language teaching. It borrows a little from traditional dictation (hence part of its name), but in fact it is quite distinct from dictation in both procedure and objectives (Wajnryb, 1990).

Dictogloss, introduced by Wajnryb (as cited in Abbasian, 2013, p. 1371), can be considered as a way for integrating form and meaning in the learning context. According to Nunan (1995), the dictogloss technique provides a useful bridge between bottom-up and top-down understanding. In the first instance, learners are primarily concerned with identifying individual elements in the text - a bottom-up strategy. However, during the small group discussions, some or all of the following top-down strategies might be employed. In all at these, the listener will integrate background inside the head knowledge with the clue picked up during the dictation. Dictogloss exploits the principle 
that two heads are better than one. Students are able to pool their resources, and even low-level learners are able, through collaborative action, to outperform their competence (Nunan, 1995, p. 28). Nassaji (as cited in Abbasian, 2013, p. 1371), suggests that using collaborative tasks requires learners to get involved in deliberate and cooperative comprehension and production of the language, e.g., through the use of dictogloss (DG) can be a way of integrating focus on form and communication by process.

Dictogloss is defined as a classroom dictation activity where learners listen to a passage, note down key words and then work together to create a reconstructed version of the text. It was originally introduced by Wajnryb (1990) as an alternative method to teaching grammar. (Vasiljevic, 2010, p. 41)

Shak (2006) considers dictogloss as a type of form-focused task which proposes to provide a meaning-focused context to raise learners' awareness of the discoursal use of the target linguistic feature. Unlike traditional dictation, there is a gap between the listening and writing phases, giving learners time to think and discuss how best to express the ideas. The aim is not to reproduce the text word for word, but to convey the meaning and style of the text as closely as possible. Furthermore, Al-Sibai (2008) regards it as an integration of both traditional and communicative notions.

According to Pica (as cited in Abbasian, 2013, p. 1371), dictogloss is an effective way to integrate traditional concerns for grammar instruction with the communicative technique of pair-work or group-work. Among the advantages of dictogloss, the one that is most empirically investigated is "meta-talk" or "Language Related Episodes" (LREs) (Rashtchi \& Khosroabadi, 2009). Qin (2008) defined LREs as "occasions where L2 learners discuss or question their language use while carrying out a reconstruction task in L2" (p. 63).

\subsection{Dictogloss Procedure to Assess the English Language Learner}

Facilitation sets are used to summarize information presented in previous lesson and or information that will occur. The purpose is to bring student attention to the current lesson. A teacher may use an outline on a board or on a transparency, or verbally present a short summary of key points or asks the learners to summarize what they have learned from previous lesson (Freinberg \& Driscoll, 1992, p. 74).

Jacobs and Small (2003) believe that "among the reasons given for advocating the use of dictogloss are that students are encouraged to focus some of their attention on form and that all four language skills" (p. 2). Furthermore, as concluded by Abbasian (2013), performing dictogloss widened the scope of their knowledge and helped them to write more for the post test. It might also be concluded that learners become more interested toward writing and this interest leads them to write more. In addition, dictogloss, which has its roots in traditional dictation exercises, typically consists of four procedures: preparation, dictation, reconstruction, and analysis with correction (Mehdiabadi \& Arabmofrad, 2014; Wajnryb, 1990).

\subsubsection{Preparation}

The first stage includes a warm-up related to the topic or a preliminary speaking or writing exercise; a group discussion around key vocabulary terms helps activate learners' prior knowledge. To conclude this stage, the teacher informs learners about what they are expected to do during the activity. (Stewart et al., 2014, p. 13)

As it is announced by Wajnryb (1990), this stage: $a$. Prepares learners for the text they will be hearing by exploiting the warm up prepares learners for the subject matter and makes them more receptive to the listening in the next stage; $b$. Prepares learner for the vocabulary of the text; $c$. Organizes learners into groups before the dictation begins.

\subsubsection{Dictation}

The first dictation and word processing systems were combined into discrete speech recognition (SR) systems, requiring the writer to speak one word at a time (Lange \& Meisel, as cited in De La Paz, 1999, p. 174). Audio signals were played by hardware or software in the computer and compared with templates (acoustic word models) already resident in the system's active vocabulary (De La Paz, 1999).

A story, news report, or other text is presented in English at a normal rate of speed. Learners listen to the dictation and take notes. The language used in the text and the length of the text depend on the learners' level of English proficiency; maturity level; and interests, needs, and learning preferences. The number of times the text is repeated and the amount of prompting required between texts will depend on the educational context; the key is to provide natural input in order to promote listening comprehension skills that enable learners to carry out the rest 
of the task. That is, listening skills are treated not as an isolated learning event but as a purposeful educative experience. (Stewart et al., 2014, p. 13)

Writing dictation through listening comprehensive is nothing more than a passive activity. It is a complex, active process in which the listener must be discriminate between sounds, understand vocabulary and grammatical structure, interpret stress, and intonation (Vandergrift, 1999). Brodkey (1972) states that dictation is a useful device for testing foreign-language proficiency.

According to Wajnryb (1990), learners should hear the dictation twice, at normal speed the first time, they should not write, but they only listen and get general feeling for the text. The second time they write down key words. When the students take notes during the dictation, they should be encouraged to write down the type of words that will help them to piece together the text in the later reconstruction stage. Such words are content or information words, for example, farmer, sold, horse, that serve as memory cues or triggers. The grammar or function words, for example, the, his, and are to be provided by the learners themselves as part of the productive of reconstructing the text.

\subsubsection{Reconstruction}

As soon as the dictation is finished, the learners, working in groups, proceed to pool their notes and work on their version of the text. The teacher's role during reconstruction is to monitor the activity but not to provide any actual language input (Wajnryb, 1990).

Students work individually or in groups to produce their versions of the original text, capturing the essence of the text and generating correct grammar. They recreate the text in their own words, trying to recall as many sequences and details as possible. This stage indicates to the teacher what students recall from the original; the teacher uses this evidence to determine whether students are keeping up or whether further instruction is required. (Stewart et al., 2014, p. 13)

\subsubsection{Analysis and Correction}

The last stage of the dictogloss procedure is the analysis and correction of the learners' text. There are various ways of conducting this. Teachers will conduct this session in their own preferred fashion: $a$. Using the board, the student's texts are written up for all to see and discuss. Sentence 1 of each group is analyzed before moving on to sentence 2 of each group; $b$. Instead of the board, an overhead projector can be used; $c$. Each text can be photocopied and the class examines them; $d$. The students can compare their version with the original sentence by sentence (Wajnryb, 1990).

Most of the students' collaboration takes place in this stage. Students self-assess their own texts and then form groups in order to conduct peer assessments. Either individually or as a group, students notice differences between their own texts and the original in regard to form, meaning, and language use. In this final stage, learners assume a more active role, relying on their individual strengths to collaborate and correct each other. Constructive criticism through peer support and teacher guidance helps form relationships that encourage students to collaborate and cooperate through social interaction. (Stewart et al., 2014, p. 13)

\section{Defining Scoring}

Jacobs et al. (1981) indicated that "there is no completely reliable basis for comparison of scores on a test unless all the students have performed the same writing task(s)" (p. 16). Students' outcomes can be assessed objectively if a reliable rating scale is utilized (Mazdayasna, 2012). Fulcher and Davidson (2007), describe scoring as it is concerned with how muches and how goods of language testing. "How we score is the link between the evidence we elicit from the task on the one hand and the construct and domain on the other" (Fulcher \& Davidson, 2007, p. 91).

A holistic scoring method may often be the choice of not only writing capability but also program managers, who may often choose holistic scoring rubrics for L2 writing assessment for some practical reasons; that is, it is more economical to assign one score to an essay by reading it once (Wiseman, 2012).

While a holistic scoring method can serve the economic interests of a program (Faghani, 2015; Wiseman, 2012), a single score based on a holistic reading of the essay may not serve the best interests of L2 writers/test takers. Holistic scoring does not allow raters to distinguish between various aspects of writing components such as control of syntax, depth of vocabulary mastery, and organizational control (Wiseman, 2012). The holistic rating is usually based on an explicit scoring guide, that is a list of specific linguistic, rhetorical or informational features of writing that the rater keeps in mind while rating the piece of text (Charney, 1984). Qualitative and quantitative methods of researching, including holistic scores, should be scrutinized for predictive and face validity. The researchers who use holistic 
scoring accept that the assessments will be valid and reliable: if the design of the training and rating sessions takes the factors necessary for reliability into account (Charney, 1984).

As an alternative, analytical scoring methods, in which raters make judgments about nominated features or writing skills, involve the separation of the various features of a composition into components for scoring purposes (Wiseman, 2012). Analytic scoring rubrics, provide more information about a test taker's performance than the single score of a holistic scoring and permit a profile of the areas of language ability that are rated. Because of that, analytic scoring methods are often chosen for placement and diagnostic purposes (Jacobs et al.; Perkins; as cited in Wiseman 2012, p. 60).

\subsection{Different Types of Scoring}

Stevick claims that "success depends less on materials, techniques and linguistic analyses, and more on what goes on inside and between the people in the classroom" $(1980$, p. 4). This indicates that there is a wide range of factors that may possibly influence the outcomes of the teaching / learning process (Herbert, 2010).

With the scoring rubric can be used as a key subcomponent in the assessment of direct writing. Holistic scoring is a global approach to the text that reflects the idea that writing is a single entity which is best captured by a single scale that integrates the inherent qualities of the writing (Wiseman, 2012).

\subsection{Scoring Methods}

Based on the units of scoring, the following six scoring procedures were developed by Farhay and Malekpour (1997, p. 207):

a. Letter Scoring Method (LSM). In this method, every letter in a word was considered a unit of scoring, i.e., an item. For example, a four-letter word such as give was considered to have four items and thus receiving four points. Spelling errors were ignored in this method.

b. Syllable Scoring Method (SYSM). In this method, every syllable in a word was taken as a unit of scoring. For example, a two-syllable word such as segment was considered to have two items and thus was given two points. Spelling errors were also ignored in this method. According to Farhady and Khani (1997, p. 9), "this system was shown to be the most reliable and valid method of all methods of scoring".

c. Morpheme Scoring Method (MSM). In this method, every morpheme in a word was considered a unit of scoring. Spelling errors were ignored unless the meaning of the word was influenced.

d. Traditional Scoring Method (TSM). In this method, every word was taken as an item. Following the traditional view of scoring dictation tests, misspelled words were considered wrong.

e. Standard Scoring Method (STSM). In this method, too, every word was an item.

However, misspelling was ignored unless it influenced the meaning of the word.

f. Chunk Scoring Method (CSM). In this method, every chunk which constituted a natural discourse boundary was taken as an item. The appropriateness of the chunks was determined by several educated native speakers who read the passages and marked the chunks. In this method, misspelling was not taken into account as long as the meaning of the chunk was preserved.

\section{Empirical Studies}

At the time of preparing this review there were many studies by implementing dictogloss task or dictation ability such as Habibi, Nemati and Habibi (2012) that have focused on and proved the positive effect of listening comprehension on dictation ability, the factor which was the pathway followed by researcher in performing dictogloss task and reached similar results.

Dictation has been proposed as a relatively simple yet reliable and valid indirect measure of functional language skills (Faghani, 2015; Savignon, 1982), and it is gaining popularity as a test of placement and proficiency in L2 programs of all kinds (Savignon, 1982). However, the unsatisfactory background of studies on improving children language learning performance, especially, their writing in pre-school age, none of the studies have focused on the fake high scoring in writing task, nor did not any of them have included preschool-aged participants whereas the present review is paid attention to. This review attempts to elaborate on a useful technique into the language teaching activities, not just English. 
Shamshiri, Aziz Mohammadi and Madani (2014) investigated the effect of oral dictation method on EFL learners' spelling accuracy and similar to the results of the Faghani and Derakhshan's (in press) and Faghani's (2015) study, they showed improvement in their participants' performance on dictation.

Correspondingly, Afsharrad and Sadeghi Benis (2014), strictly believe that improving learners' ability in taking dictation improves their language proficiency. They have proved their claim by performing transcription that has a significant positive effect on learners' dictation and recommended that transcribing exercise is a techniques to help elementary learners improve their language proficiency which is in much parallel to this study's results with some small differences. That is, here, fake high scores using dictogloss that also contains transcribing, is proved to have positive effect on young learners' dictation ability.

Equally, on dictogloss case, Mehdiabadi and Arabmofrad (2014) have recently done a study to prove the significant effect of collaborative dictogloss on emotional intelligence (IE). While, few studies have focused on fake high scoring but none of them was in the EFL or any other language learning field. Farhady and Malekpour (1997) have done many studies on dictation ability, with the similar pathway to the Faghani and Derakhshan's (in press) and Faghani's (2015) study, though different results. In a similar line, Farhady (1997), Farhady and Khany (1997) used and suggested dictation as a language proficiency test.

Ezenwosu (2011), regarding his/her results, concluded that there should be consistent application of dictation activities to help making significant contributions to the current school reform project of the learners which is alike a study by Faghani (2015) and Faghani and Derakhshan (in press) which showed the positive outcome of dictogloss combined by fake scoring on learners' performance improvement. The results of her study demonstrated that regardless of the noticeable weakness of the learners at the beginning of the study, they showed significant improvements in performing their tasks during the treatment sessions. But with a different aim, Marzban and Abdollahi (2013) have revealed that dictation had a significant effect on the listening comprehension ability of the learners. The weight of their study was mostly on listening comprehension, indeed, through a regular practice with partial dictation, they proved an improvement in learners' listening comprehension. While, in Faghani and Derakhshan's (in press) and Faghani's (2015) study, dictation ability was dependent on receiving fake high scores.

According to Farhady and Malehpour's (1997) findings through investigating the effect of different scoring methods on the psychometric characteristics of dictation tests, there must have been a weak relationship between the method of scoring and the reliability and validity of dictation tests; moreover, trait structures of dictation tests would have been independent of the scoring methods but related to the students' proficiency level. And regarding the last important result, there should have been no relationship between the scoring methods and the students' performance. Though, in a study by Faghani (2015) it is proved with the $p$-value $=0.0005$, showing a very high level of significance, that fake high scoring, which can be considered as a scoring method, has had a very great effect on the learners performance and caused them a significant improvement in dictation ability, and even a strongly positive correlation between fake high scores and learners' improvement. This discrepancy could be justified on the ground that different participants in Farhady and Malekpour's (1997) study were in university age and level, but in the Faghani's (2015) and Faghani and Derakhshan (in press) study, they were at pre-school age, so they were not aware enough of the validity of scores given to them. Another difference between these two studies is that Farhady and Malekpour (1997) had investigated the effects on whole proficiency level, but Faghani (2015) and Faghani and Derakhshan (in press) focused only on dictation ability.

Many studies, though, have focused on different aspects or effects of dictation and dictogloss tasks, for example, Xiangdong and Chunyan (2012) have worked on validity of dictation tests. And they revealed that learners' actual performance does not apparently relate to the instructions given in the compound dictation test, which may raise doubts over the effectiveness of the instruction sand may pose a potential warning to test validity.

Foulds and Warehime (1971) managed the Personal Orientation Inventory (POI) twice, 1st under regular testing situation and then under a fake good condition and at the end of their study, they suggest that POI scores are unlikely to be inflated by the endeavors of students to make a good impression on the inventory. Likewise, Vargo and Semple (1984) have studied on the Attitudes Toward Disabled Persons (ATDP) Scale - Form A twice in one sitting, once with honest views and once with those that believed to gain the highest (i.e., most positive) score. And their results showed that fake score were meaningfully higher than the mean honest score, proving that students did fake well. Although these studies seem to have no relation to the language learning area, they can show the potential of fake scoring to be used in academic studies.

It should be stated that our learners are the key part and the base point of any learning process, so we need to provide some techniques to make them more eager and active with a strong feeling of capability of learning and being 
successful (Faghani, 2015). In performed pathway in this research, the learners could achieve a sense of success and victory and feeling to have the ability that they can do what other students actually can and according to Mehdiabadi and Arabmofrad (2014, p. 137) "they will gradually be more engaged in showing their competence" and "enrich their self-confidence, motivation to learn and the individual's ability to solve the learning problems" especially in dictation writing, which was the aim of this study.

Foulds and Warehime (1971) have administered the Personal Orientation Inventory (POI) twice to 95 undergraduates, 1 st under ordinary testing conditions and then under a "fake good" condition. They suggest that POI scores are unlikely to be inflated by the conscious or unconscious attempts of students to make a good impression on the inventory when they have little knowledge of the self-actualizing model of man.

Farhady and Khany (1997) state that dictation can be scored quite objectively. Vargo and Semple (1984) have used the Attitudes Toward Disabled Persons (ATDP) Scale twice in 1 sitting, responding once with their honest views and once with the responses that they believed would yield the highest (i.e., the most positive) score. A one-tailed $t$ test for correlated samples showed the mean fake score to be significantly higher than the mean honest score, indicating that students were able to "fake well." They discussed it in terms of the use of the ATDP scale with both rehabilitation and nonrehabilitation populations. Similarly, Peeters and Lievens (2005) had released that the scores of students in the fake condition were significantly higher than those of students in the honest condition. As well, Stein and Graham (1995) had administered the students under instructions to fake good, fake bad, or score honestly and reported significant $(p<.001)$ difference on all validity scale scores of the three groups of respondents.

Callinan and van der Zee (2010) have done a case study on teaching of reading in English, and investigated how reading ability for words and non-words as well as short-term memory ability for words and phonemes improves in Reception level children (4 to 5 years) in three different schools using two different methods of reading instruction. This empirical research has focused on contrasting synthetic phonics teaching with analytic phonics, where words and word parts are taught before individual graphemes. And indeed, research has shown that synthetic phonics can be successful while no effects of gender on reading ability were found.

Vargo and Semple (1984) have studied on a physical therapy program completed the Attitudes Toward Disabled Persons (ATDP) Scale - Form A twice in one sitting, responding once with their honest views and once with the responses that they believed would gain the highest (i.e., most positive) score. A one-tailed t test for correlated samples indicated the mean fake score to be meaningfully higher than the mean honest score, indicating that students were able to fake well.

Farhady (1997) has investigated the effect of different scoring methods on the psychometric characteristics of dictation tests. He concluded that there was a weak relationship between the scoring method and the reliability and validity of dictation tests; trait structures of dictation tests were related to the students' proficiency level but independent of the scoring methods. That is, regardless of the scoring method, two underlying traits were detected which might be called listening comprehension and reconstruction abilities. Nevertheless, by increasing the proficiency level, the differences in the loadings on the two factors decreased; and, there was no relationship between the methods of scoring and the students' performance.

According to Xiangdong and Chunyan (2012), dictation has long been used in foreign language teaching and testing. Accordingly, various empirical studies have been conducted to investigate the validity of the dictation test.

Shamshiri et al. (2014) have investigated the effect of oral dictation method on EFL learners' spelling accuracy. To carry out this study, they chose their participants among third grade guidance school in Komijan province at two intact classes. Descriptive statistics revealed that both groups showed improvement in their performance on dictation. With respect to the components of the test, the experimental group that used oral dictation showed higher improvement in their dictation skills. Control group learners' showed no significant improvement in their dictation skills by practicing partial method.

Xiangdong and Chunyan (2012), in their study explored the relationships between the test-takers' actual performance and the instructions for the compound dictation test, the language abilities measured, any major construct-irrelevant factors affecting the test-taking processes, and the performance patterns of performance across test-takers of different overall proficiency levels. Results showed that test-takers may pay more attention to the pronunciation of the words to be used to fill the blanks than to the actual meaning of the words, their difficulties in spelling and sentential expression possibly interfering with test performance. A number of construct-irrelevant factors posing a potential threat to test validity were found in the test-taking processes which some of them are related to the test-takers, such as memory capacity, attention failure and psychological factors, while others relate to the test, including speech rate 
and time constraints. Test-takers in the study at all three proficiency levels appeared not to follow the instructions given in the compound dictation test.

Considering that dictation tests tap learners' overall language proficiency, it is logical to think that improving learners ability in taking dictation improves their language proficiency. Afsharrad and Sadeghi Benis (2014) in their study have considered dictation as an end and have proposed transcribing as a technique to improve it, and have examined the effect of transcribing on dictation. Their findings indicated that transcribing has a significant positive effect on learners' dictation. So, transcribing exercise can be considered as one of the techniques to help elementary learners improve their language proficiency.

Habibi et al. (2012) have done a study in Kurdistan is ample to show the role of listening comprehension in dictation, as an integral part of language learning, in the development of EFL curriculum. They had placed their participants in Modern group and Traditional group, and their findings revealed that the increasing in dictation scores in the modern group was higher than in the traditional group. Traditional approaches are not as useful as the processing examined processing listening comprehension in their study. On the other hand, dividing the students into two groups for joint activities would result in better comprehension and motivate the less talented ones to learn new dictation presented through listening comprehension. Hence, they have concluded that listening comprehension has a direct impact on the improvement of dictation.

Ezenwosu (2011) contends that effective use of dictation activities will help to improve students' proficiency in the four aspects of English language among the second learners of English language in a country like Nigeria. He suggests that the curriculum planners at the secondary school level have to priorly include dictation activities in the syllabuses. It is concluded in that research that there must be consistent application of dictation activities.

Kavaliauskienè and Darginavičienè (2009) have revealed that class dictations of authentic materials are beneficial to students at tertiary level, as they help perfect listening and writing skills and increase awareness of problematic language areas. They believe that class dictations are designed to create a friendly learning environment in which students cooperate in pairs or small groups. Dictation activities also provide opportunities for each learner to compare her/his written work with a peer's work. Furthermore, post-dictation comprehension exercises proved beneficial, but pre-teaching vocabulary might be optional depending on the students' general proficiency level in language. Finally, selfchecking of ones written work by comparing it with original texts of the dictated material allows students to assess their achievements individually.

In order to help EFL students to avoid making grammatical, comprehension and spelling errors in writing EFL, Lahad (2007) have recommended that: 1) Grammar lessons need to emphasize specific aspects like; addition of some prefix, making plural and accompanied changes. 2) Comprehension lessons should give students practice in identifying some words that have the same pronunciation but different meanings. 3) Dialogue and conversation drills should be centered on the problematic sounds. 4) In phonetic lessons students need to be acquainted with different ways of pronouncing the same letters or combinations of letters and given exercises to discover spelling rules. 5) Students need to recognize that there are some letters which can produce two sounds. 6) Students should practice the spelling of words that contain problematic sounds.

Marzban and Abdollahi (2013) have investigated the effects of partial dictation on the listening comprehension (LC) ability of Iranian intermediate EFL learners. The participants took a listening test as a pre-test. For one term, the students in the control group were given the listening exercises in their textbook. The experimental group, in addition to the listening exercises in the textbook, was given partial dictation 11 times during the term. At the end of the term the LC ability of both groups was post-tested with the same listening test which was also used as the listening pre-test. Results of their study showed that dictation had a meaningful effect on the listening comprehension ability. The mean gain scores of the experimental group were significantly higher than those of the control group.

\section{Conclusions and Implications}

This review attempted to study and find out the possible way to help very young language learners in their dictation writing or, perhaps, other writing activities. Regardingly, the output suggests that fake high scoring using dictogloss task had a strongly positive effect on weak learners' real scores in their dictogloss performance (Faghani \& Derakhshan, in press). As a final point, they could prove significant improvements in performing dictogloss tasks during the treatment sessions despite, the noticeable weakness of the learners at the beginning of the study, and it got verified that giving fake high scores to kids' dictogloss tasks during a permanent process would lead them to be more capable of writing dictation. That seems to be caused by improving their sense of confidence and inspiration which made them be keener and more active in performing their tasks. Ghaffarzade (2013) in her paper on active vs. passive dictation, 
elaborates on new dictation strategies as a solution to reduce the deficiencies of traditional dictation. The aim of all of them is to assist learners using the language productively.

\subsection{Consulting and Dictation}

An alternative method is firstly reading a text and asking the learners to listen to it. After listening they can write as many key words as they can. Besides learners listen for the whole text to gain the overall meaning and they can improve note-taking skills. Both accuracy and meaning are important in this method (Ghaffarzadeh, 2013).

\subsection{Brainstorming and Dictation}

The students can construct the story based on their ideas, emotions and creativity. Constructing and telling a story will attract their attention and motivate learners to learn. It can assists learners to promote listening \& constructing sentences meanwhile writing. And after all to learning (Ghaffarzadeh, 2013).

\subsection{Listen and Answer}

According to Ghaffarzadeh (2013) the learners instead of writing what the teacher dictates to them, must write their own answers.

\subsection{Trans-Dictation}

Farhady and Khany (1997), trans-dictation (a combination of translation and dictation) is produced to reduce the insufficiencies of traditional dictation. The use of "Translation" and "Dictation" as teaching and testing devices in ESL/EFL has a long history. In which the teacher reads the text at normal speed while the learners are listening to it. Then the teacher reads it again at normal speed and the students try to translate it and after reading their translations they try to write the dictation. Farhady and Khany (1997) believe that psycholinguistically, the transdictation is an improvement over both translation and dictation type tests and psychometrically, it is proved to be a highly valid and reliable measure of language proficiency.

\subsection{Correcting the Mistakes}

Ghaffarzadeh (2013) states that the teacher will give the learners a written text containing some spelling or grammatical mistakes. Afterwards the teacher will read it at normal speed again while the learners are identifying the mistakes.

\subsection{Gaps and Dictation}

In this method the teacher can make some blanks in a text and ask the students to work in pairs to fill them (Ghaffarzadeh, 2013).

\section{a) Art and Dictation}

This is an involving and motivating method. At the first step, the teacher dictates the text while the learners listen to. The text is constructed in such a manner that the learners can draw some pictures. Then the students try to write what they see. Dictation will be corrected a discussion will be hold on in which the mistakes will be identified (Ghaffarzadeh, 2013).

\section{b) Cleaning - Rewriting Procedure}

In this procedure, the teacher reads a text at normal speed and all of the students listen. Then he starts reading it sentence by sentence, while a representative from each group writes it on the board. After ending the text, the other members of each group guide their leaders to correct the errors and time limitation may be held (Ghaffarzadeh, 2013).

\section{c) Learner-Centered Dictation}

Sometimes using the students as the "dictators" has the benefit of focusing on the pronunciations of learners. One of the techniques is to distribute different parts of a text among the learners, hence each student should dictate his own part and others will write it (Ghaffarzadeh, 2013).

\section{d) Cheating and Dictation}

If teachers be able to use even the negative activities like cheating by students in their teaching process, they can be more successful. In this procedure, the teacher reads an interesting story-like text, while learners are listening to it. Then he reads it and students write. Afterwards, the teacher asks the learners to open their books, consult with other learners and use every instrument or strategy to correct their mistakes (Ghaffarzadeh, 2013). 
Several pedagogical implications appeared from the results of the investigated research. To begin with, according to Faghani and Derakhshan (in press) an endeavor must be to add to the children EFL learners' reform process, encouraging an effective method of engaging and improving very young EFL learners which indeed, implies well handling difficulties and challenges due to being patient and tolerant that might impede the teaching implementation. For much pedagogical practice, adjustments and adaptations in teachers' role will be needed regarding the atmosphere of the classroom in order to allow some opportunities for learners to be more confident and be able to rely on themselves as well as being more motivated. Nevertheless, the authority of teachers' traditional character is required to be lessened. Overall, the results of Faghani and Derakhshan (in press) indicated that some amount of lowering the strictness would help a lot in learners' learning process. Having the knowledge of motivating and engagement necessitates the teachers to put their viewpoint conception of education aside so that they can engage their learners in learning and being capable of success. Teachers are also expected to apprehend that they are not in bondage of a fixed method; hence, they can bring necessary supplementary and remedial treatments into their classrooms. According to Mehdiabadi and Arabmofrad (2014), dictogloss, which is known as a collaborative task and also one of the output-oriented activities, can be used both individually and collaboratively. As in Faghani's (2015) and Faghani and Derakhshan's (in press) study the dictogloss was performed to be done individually by the learners, future studies can investigate the use of cooperative dictogloss within small or bigger groups with the same or similar procedure.

Furthermore, the differentiation of male and female subjects can be a case to be considered in further research. As a last comment, syllabus designers and teacher training instructors are expected to include any techniques to give more weight to motivating the learners as one possible pathway to solve similar problems, like this study, teachers should not be afraid of the possible side-effects of such procedures. Likewise, in Faghani and Derakhshan's (in press) and Faghani's (2015) study, results indicated that fake high scoring on a permanent dictogloss task was a suitable, applicable, and appropriate device for EFL teachers and students to achieve their educational goals and the aims of the language department. The findings of research could also support those who are ELT curriculum developers, syllabus designers, education centers, and everyone involved in learning and teaching process especially in the field of teaching English as a foreign language to kids.

\section{References}

Abbasian, G. R. (2013). The effectiveness of dictogloss in developing general writing skill of Iranian intermediate EFL learners. Journal of Language Teaching and Research, 4(6), 1371-1380. http://dx.doi.org/10.4304/jltr.4.6.1371-1380

Afsharrad, M., \& Sadeghi Benis, A. R. (2014). The effect of transcribing on beginning learners' dictation. Theory and Practice in Language Studies, 4(10), 2203-2208. http://dx.doi.org/10.4304/tpls.4.10.2203-2208

Al-Sibai, D. M. M. (2008). Using dictogloss tasks: Attention to form in a collaborative classroom activity with female students at King Saud University. Unpublished M. A. thesis, King Saud University, Proquest. Also, http://mpazhou.ir/wp-content/uploads/Characteristics-of-Dictation-Tests.pdf

Anderson, D. L., Standerford, N. S., \& Imdieke, S. (2010). A self-study on building community in the online classroom. An Online Journal for Teachers Research, 12(2), 1-10.

Bennett, W. A. (1968). Aspects of language and language teaching. London, UK: Cambridge University Press.

Bollin, G. G. (2003). The realities of middle school for Mexican children. The Clearing House, 76(4), 198-201. http://dx.doi.org/10.1080/00098650309602002

Britzman, D. (1991). Practice makes practice: A critical study of learning to teach. Albany, NY: State University of New York Press.

Brodkey, D. (1972). Dictation as a measure of mutual intelligibility: A pilot study. Language Learning, 22, 203-217. http://dx.doi.org/10.1111/j.1467-1770.1972.tb00083.x

Callinan, C., \& van der Zee, E. (2010). A comparative study of two methods of synthetic phonics instruction for learning how to read: Jolly Phonics and THRASS. The Psychology of Education Review, 34(1), 21-31.

Charney, D. (1984). The validity of using holistic scoring to evaluate writing: A critical overview. Research in the Teaching of English, 18(1), 65-81.

Coopersmith, S. (1967). The antecedents of self-esteem. San Fransisco: Freeman. 
Davis, P., \& Rinvolucri, M. (2002). Dictation, new methods, new possibilities. Cambridge, UK: Cambridge University Press.

De La Paz, S. (1999). Composing via dictation and speech recognition systems: Compensatory technology for students with learning disabilities. Learning Disability Quarterly, 22(3), 173-182. http://dx.doi.org/10.2307/1511284

Ezenwosu, N. E. (2011). Dictation as a veritable tool for language proficiency on project educational reform in Nigeria. An International Multidisciplinary Journal, Ethiopia, 5(6), 23, 18-25. http://dx.doi.org/10.4314/afrrev.v5i6.2

Faghani, B. (2015). The effect of fake high scores using dictogloss on four to seven year old children's dictation ability (Unpublished master's thesis). Department of English Language Teaching, Gorgan Branch, Golestan Science and Research Branch, Islamic Azad University, Gorgan, Iran

Faghani, B., \& Derakhshan, A. (in press). Moving towards an action research: The effect of fake high scoring using a dictogloss task on four to seven year old children's dictation ability. The Asian Journal of English Language and Pedagogy.

Farhady, H. (1997). Different methods of scoring and the psychometric characteristics of dictation tests [Abstract]. Retrieved December 2014 from http://www.researchgate.net/publication/237746515_Different_Methods_of_Scoring_and_the_Psychometric_C haracteristics_of_Dictation_Tests

Farhady, H., \& Khany, R. (1997). Transdictation as a measure of language proficiency. In translation conference, Tabriz, Iran.

Farhady, H., \& Malekpour, M. (1997). Different methods of scoring and the psychometric characteristics of dictation tests. Journal of Social Sciences and Humanities, 12(1), 203-216.

Foulds, M. L., \& Warehime, R. G. (1971). Effects of a "fake good" response set on a measure of self-actualization [Abstract]. Journal of Counseling Psychology, 18(3), 279-280. http://dx.doi.org/10.1037/h0030846

Freinberg, J. H., \& Driscoll, A. (1992). Universal teaching strategies. Boston Allyn and Bacon.

Fulcher, G., \& Davidson, F. (2007). Language testing and assessment, an advanced resource book. London and New York: Routledge Publications.

Ghaffarzade, H. M. A. (2013). Active vs. passive dictation. International Journal of Evaluation and Research in Education (IJERE), 2(3), 129-134. http://dx.doi.org/10.11591/ijere.v2i2.1717

Goodlad, J. (1984). A place called school: Prospects for the future. New York: Mcgraw-Hill.

Habibi, P., Nemati, A., \& Habibi, S. (2012). The role of listening comprehension in dictation. Indian Journal of Science and Technology, 5(8), 3208-3210.

Hansen, R. (1995). Teacher socialization in technology education. Journal of Technology Education, 6(2), 34-45.

Harris, D. P. (1969). Testing English as a second language. New York: McGraw-Hill.

Herbert, P. (2010). Beyond materials, techniques and linguistic analyses: The role of motivation, beliefs and identity.

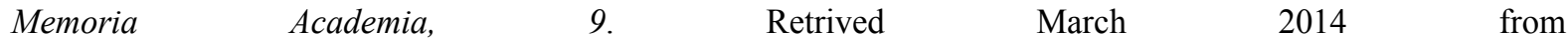
http://www.memoria.fahce.unlp.edu.ar/art_revistas/pr.4918/pr.4918.pdf

Jacobs, G., \& Small, J. (2003). Combining dictogloss and cooperative learning to promote language learning. The Reading Matrix, 3(1), 1-15.

Jacobs, H., Steven, A., Deanne, R. Wormuth, V., Faye, H., \& Jane, B (1981). Testing ESL composition: A practical approach. Rowley, Massachusetts: Newbury house Publishers, Inc.

Jafarpur, A., \& Yamini, M. (1993). Does practice with dictation improve language skills? System, 21, 359-369. http://dx.doi.org/10.1016/0346-251X(93)90026-D

Kaga, M. (1991). Dictation as a measure of Japanese proficiency. In O. Kamada \& W. Jacobson (Eds.), On Japanese and how to teach it (pp. 112-124). Tokyo: Japan Times. http://dx.doi.org/10.1177/026553229100800202

Kavaliauskienè, G., \& Darginavičiene, I. (2009). Dictation in the ESP classroom: A tool to improve language proficiency. English for Specific Purposes World, 8(23), 1-10. 
Kumaravadivelu, B. (2003). Beyond methods: Macrostrategies for language teaching. New Haven and London: Yale University Press.

Lado, R. (1961). Language testing. New York: McGraw-Hill.

Lahad, A. M. (2007). Identifying errors made by EFL college students in dictation. Journal of College of Basic Education, 52, 41-52.

Marzban, A., \& Abdollahi, M. (2013). The effect of partial dictation on the listening comprehension ability of Iranian intermediate EFL learners. International Research Journal of Applied and Basic Sciences, 5(2), 238-244.

Mazdayasna, G. (2012). Objective assessment of oral presentations and EFL learners' speaking development. Sheikhbahaee EFL Journal, 1(1). 23-38.

Mehdiabadi, F., \& Arabmofrad, A. (2014). The effectiveness of collaborative output task of dictogloss in enhancing EFL learners' Emotional Intelligence. International Journal of Linguistics, 6(6). 128-142. http://dx.doi.org/10.5296/ijl.v6i6.6804

Nevola, F. (2002). A personal response to Debbie Hepplewhite's "An evaluation of the NLS from a teacher's perspective" from the RRF Newsletter, 48. Retrieved April 2014 from http://www.rrf.org.uk/archive.php?n_ID=91\&n_issueNumber=49.

Nunan, D. (1995). Language teaching Methodology: A textbook for Teacher. Great Britain: Prentice Hall Europe.

Oller, J. W. (1972). Dictation as a device for testing language proficiency. Workpapers in TESL: UCLA, 37-42.

Oller, J. W. (1979). Language tests at school. London: Longman.

Peeters, H., \& Lievens, F. (2005). Situational Judgment Tests and their predictiveness of college students' success: The influence of faking. Educational and Psychological Measurement, 65(1), 70-89. http://dx.doi.org/10.1177/0013164404268672

Prabhu, N. S. (1987). Second language pedagogy. Oxford: Oxford University Press.

Qin, J. (2008). The effect of processing instruction and dictogloss tasks on acquisition of the English passive voice. Language Teaching Research, 12(1), 61-82. http://dx.doi.org/10.1177/1362168807084494

Rahimi, M. (2008). Using dictation to improve language proficiency. Asian EFL Journal, 10(1), 33-47.

Rashtchi, M., \& Khosroabadi, P. (2009). The comparative effect of explicit focus on form and dictogloss task on learning English tenses. SID, JELS, 1(1). 101-114.

Richards, J. C., \& Schmidt R. (2002). Longman dictionary of language teaching and applied linguistics ( ${ }^{\text {rd }}$ ed.). London: Pearson Education.

Rivers, W. M. (1968). Teaching foreign language skills. Chicago: University of Chicago.

Savignon, S. J. (1982). Dictation as a measure of communicative competence in French as a second language. Language Learning, 32, 33-47. http://dx.doi.org/10.1111/j.1467-1770.1982.tb00517.x

Shak, J. (2006). Children using dictogloss to focus on form. Reflections on English Language Teaching. 5(2), 47-62.

Shamshiri, H. R., Aziz Mohammadi, F., \& Madani, D. (2014). The impact of oral dictation on improving EFL learners' spelling accuracy [Abstract]. Enjoy Teaching Journal, 2(1). Retrieved December 2014 from http://lieee.org/index.php/etj/article/view/44

Stein, L. A. R., \& Graham, J. R. (1995). Detecting fake-bad MMPI-A profiles. Journal of Personality Assessment, 65(3), 415-427. http://dx.doi.org/10.1207/s15327752jpa6503_3

Stevick, E. W. (1980). Teaching languages. A way and ways. Newbury House, Rowley, Mass.

Stewart, B. L., Silva, L. H. R., \& González J. A. T. (2014). Integrating language skills through a dictogloss procedure. English Teaching Forum, 2, 12-19, 35.

Tomlinson, B. (2010). Principles of effective materials development. In N. Harwood (Ed. 1), English language teaching materials: Theory and practice (pp. 81-108). United States: Cambridge University Press.

Vandergrift, L. (1999). Facilitating second language listening comprehension: Acquiring successful strategies. ELT Journal, 53(3), 168-176. http://dx.doi.org/10.1093/elt/53.3.168 
Vargo, J. W. \& Semple, J. E. (1984). Honest versus fake scores on the Attitudes Toward Disabled Persons scale-Form A [Abstract]. Rehabilitation Counseling Bulletin, 27 (3), 182-185.

Vasiljevic, Z. (2010). Dictogloss as an interactive method of teaching listening comprehension to 12 learner. English Language Teaching, 3(1), 41-52. http://dx.doi.org/10.5539/elt.v3n1p41

Wajnryb, R. (1990). Grammar dictation. Oxford: Oxford University Press.

Walia, D. N. (2012). Traditional teaching methods vs. CLT: A study. Frontiers of Language and Teaching, 3, 125-131.

Wiseman, C. S. (2012). A comparison of the performance of analytic vs. holistic scoring rubrics to assess L2 writing. Iranian Journal of Language Testing, 2(1), 59-92.

Xiangdong, G., \& Chunyan, S. (2012). A retrospective study on test-takers' cognitive and metacognitive processes in taking a compound dictation test. Chinese Journal of Applied Linguistics, 35(4), 400-420. 